Journal of Engineering and Applied Sciences 14 (9): 2822-2829, 2019

ISSN: 1816-949X

(C) Medwell Journals, 2019

\title{
Comparative Study of Control Strategies for a Micro Grid DC System of Renewable Energy Sources
}

\author{
Oswaldo Rivera, Mauricio Mauledoux, Angie Valencia, Oscar Caldas and Oscar Aviles \\ Faculty of Mechatronics Engineering, Universidad Militar Nueva Granada, Bogota, Colombia
}

\begin{abstract}
This study presents a comparative study of a Generalized Predictive Controller (GPC) with a classical Proportional-Integral-Derivative (PI) controller and the Model Predictive Controller (MPC). All these strategies are compared on their output response, steady state error, controller effort and disturbances rejection. These controllers were designed and evaluated to be implemented and work on a micro grid DC system located at the Universidad Militar Nueva Granada Campus in Cajica, Colombia. Disturbances in this study were predicted by Nonlinear Autoregressive with Exogenous Excitation Artificial Neuronal Networks Model (NARX).
\end{abstract}

$\underline{\text { Key words: Generalized predictive control, PID, MPC, micro grid DC, nonlinear autoregressive, system }}$

\section{INTRODUCTION}

For many decades, almost all the electricity consumed in the world has been generated from three different forms of power plant: fossil, hydro and nuclear (Anonymous, 2017a, b), nonetheless, issues such as global warming, the pollution of the air, water and land, the production of acid rain or the health threats caused by burning fossil fuels have forced society to find new ways to generate electrical energy.

Due to these problems, the international organisms have started to create and promote new policies about the use green-energy technologies, taxes on fossil fuels, capital subsidies for investment on renewable energy, international sanctions for polluting, among others (Olivares et al., 2014).

Even when in 2016 the energy related carbon dioxide emissions from fossil fuels and industry were nearly flat and the coal use decrease significantly (Anonymous, 2017a, b) in Colombia, according to the Mines and Energy Ministry, around $52 \%$ territory is not interconnecting to the grid (Anonymous, 2014), even more, inside these areas, there are 5 main cities of the country. These cities supply their demand of electrical energy through fossil power plants which increase contamination levels inside those areas.

Obeying to the ongoing trends in renewable energies, terms like smart grid and micro grid appear as a possible and affordable solution for the Colombian issue. A smart grid is an electrical grid which includes a variety of operational and energy measures including smart meters, smart appliances, renewable energy resources and energy efficient resources (Anonymous, 2008) in the other side, a micro grid is a small, independent power system which increase reliability with distributed generation, efficiency with reduced transmission length and CHP (Combined Heat and Power) at the same time, this kind of grids integrate alternative energy sources easier than conventional grids (Mork and Weaver, 2009).

The study proposed in this study aims to increase the efficiency and performance of this kind of systems. Besides to compare these three controllers it was included a NARX Model (Mauldeoux et al., 2015) to predict de disturbances that would interact with the micro grid and the controller. The model seeks to enhance the efficiency of the micro grid and replace the sensors that acquire the disturbances data in case they fail.

GPC is capable of stable control of processes with variable parameters, variable dead-time and with a model order which changes instantaneously (Clarke et al., 1987). This method has become one of the most popular Model Predictive Control MPC methods both in industry and academia. It has been successfully implemented in many industrial applications, showing good performance and a certain degree of robustness (Chidrawar and Patre, 2008). We improved the robustness of this controller through CARIMA (Holkar and Waghmare, 2010) model application in this way it ensures an optimal performance of the micro grid. As this system reads the input signals given by the sensors placed in the micro grid it will know how the performance of micro grid will be and the controller will determinate how much current will pass from the alternative energy to the load powered by the micro grid. Instead of having a reactive control which only detects

Corresponding Author: Oswaldo Rivera, Faculty of Mechatronics Engineering, Universidad Militar Nueva Granada, Bogota, Colombia 


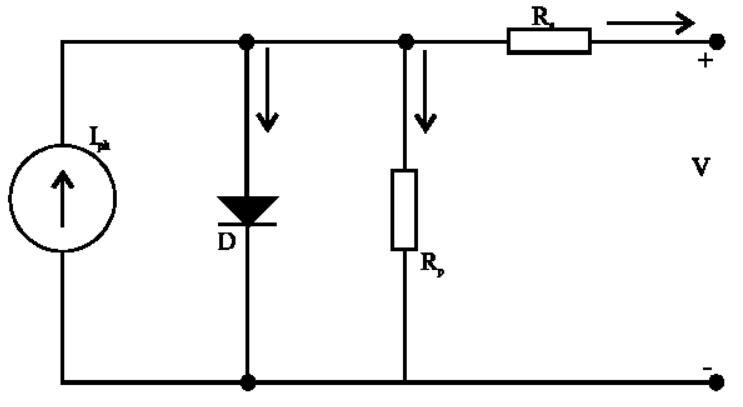

Fig. 1: Photovoltaic model representation

when the load in battery is below of $70 \%$, the predictive controller will anticipate that and will proceed according the previous setup in the micro grid.

Micro-grid modelling: In order to identify the micro-grid system it is necessary to represent each one of its components, mathematical models are proposed next.

Photovoltaic model: A Photovoltaic panel (PV) module is represented as two nodes electrical circuit with the sunlight emulated as a current source, a diode connected in antiparallel and a series and parallel resistances as shown in Fig. 1.

Then, the equation that defines the PV Model dynamics in terms of an output current can be obtained via. Kirchhoff's current law as shown in Eq. 1:

$$
\mathrm{I}=\mathrm{I}_{\mathrm{ph}}-\mathrm{I}_{\mathrm{d}}-\mathrm{I}_{\mathrm{p}}
$$

where, $I_{p h}, I_{d}$ and $I_{p}$ are defined in Eq. 2-4:

$$
\begin{gathered}
\mathrm{I}_{\mathrm{ph}}=\frac{\mathrm{G}}{\mathrm{G}_{\mathrm{ref}}}\left(\mathrm{I}_{\mathrm{ph}, \text { ref }}+\mu_{\mathrm{sc}} \cdot \Delta \mathrm{T}\right) \\
\mathrm{I}_{\mathrm{d}}=\mathrm{I}_{\mathrm{o}}\left|\exp \left(\frac{\mathrm{V}+1 \cdot \mathrm{R}_{\mathrm{s}}}{\alpha}\right)-1\right| \\
\mathrm{I}_{\mathrm{p}}=\left(\frac{\mathrm{V}+\mathrm{I} \cdot \mathrm{R}_{\mathrm{s}}}{\mathrm{R}_{\mathrm{p}}}\right)
\end{gathered}
$$

Where:

$\mathrm{G}=$ The irradiance

$\mathrm{G}_{\mathrm{ref}}=$ The irradiance at standard conditions

$\mathrm{T}_{\mathrm{c}}=$ The cells temperature

Thus, $\mathrm{T}=\mathrm{T}_{\mathrm{c}}-\mathrm{T}_{\mathrm{c} \text {, ref }}\left(\mathrm{T}_{\mathrm{c}, \text { ref }}=298 \mathrm{~K}\right)$ and $\mu_{\mathrm{sc}}=$ The coefficient temperature of short circuit.
Wind turbine model: To model a wind turbine starts defining the static and mechanical characteristics. The Tip-Speed Ratio (TSR), denoted by $\lambda$ is the radio between the linear speed as shown in Eq. 5, calculated by the rotor radius and angular speed:

$$
\lambda=\frac{\mathrm{r}_{\mathrm{r}} \cdot \mathrm{w}_{\mathrm{r}}}{\mathrm{V}_{\mathrm{w}}}
$$

The TSR and the user-defined blade pitch angle are used to calculate the rotor power coefficient, denoted by $\mathrm{C}_{\mathrm{p}}$ as shown in Eq. 6 (Tang et al., 2011).

$$
C_{p}=\frac{P_{r}}{P_{w}}
$$

Where:

$\mathrm{P}_{\mathrm{w}}=$ The power of wind

$\mathrm{P}_{\mathrm{r}}=$ The power of rotor

Finally, the state equation is presented in the Eq. 7 , with the output in the current $i_{\mathrm{g}}$ :

$$
\left[\begin{array}{c}
\dot{\mathrm{w}}_{\mathrm{re}} \\
\dot{\theta}_{\mathrm{re}} \\
\dot{\mathrm{l}}_{\mathrm{g}}
\end{array}\right]=\left[\begin{array}{ccc}
-\frac{\mathrm{B}_{\mathrm{r}}}{\mathrm{J}_{\mathrm{r}}} & 0 & 0 \\
1 & 0 & 0 \\
\frac{\mathrm{L}_{\mathrm{I}}}{\mathrm{L}_{\mathrm{g}}} & 0 & -\frac{\mathrm{R}_{\mathrm{rot}}}{\mathrm{L}_{\mathrm{g}}}
\end{array}\right]\left[\begin{array}{c}
\mathrm{w}_{\mathrm{re}} \\
\theta_{\mathrm{re}} \\
1_{\mathrm{g}}
\end{array}\right]+\left[\begin{array}{c}
\frac{1}{\mathrm{~J}_{\mathrm{re}}} \\
0 \\
0
\end{array}\right]+\mathrm{T}_{\mathrm{r}}
$$

Battery model: The battery model can be expressed by the open circuit Voltage $\left(\mathrm{V}_{\mathrm{oc}}\right)$ or Electromotive Force (EMF) $E_{0}$, the battery Voltage $V_{t}$, the internal Resistance $\mathrm{R}_{\mathrm{i}}$, the discharge current $\mathrm{i}$ and the State of Charge (SOC) $Q$ as shown in the Eq. 8 and 9:

$$
\begin{gathered}
E=E_{0}-K \frac{Q}{Q-\int i d t}+A_{e}^{-B \int i d t} \\
V_{t}=E-R_{i} \cdot i
\end{gathered}
$$

Where:

$\mathrm{Q}=$ The maximum battery capacity

$\mathrm{A}=$ The exponential amplitude

$\mathrm{K}=$ The polarization voltage constant

$\mathrm{B}=$ The time constant inverse capacity

The battery voltage obtained is given by Eq. 10 :

$$
E_{\text {batt }}=E_{0}-K \frac{Q}{Q-i t}-R_{i}-K \frac{Q}{Q-i} \cdot i^{*}+A_{e}^{-B . i t ~}
$$




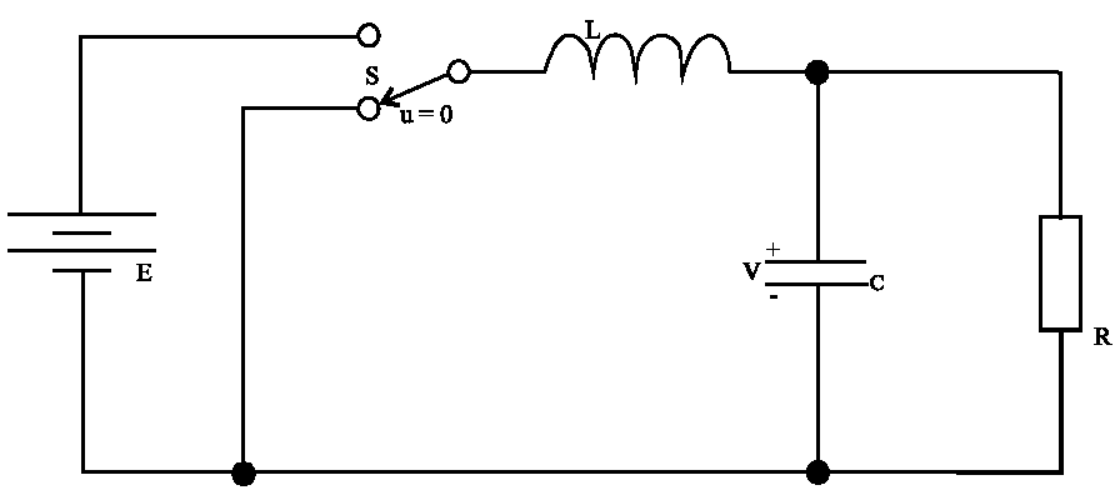

Fig. 2: Buck converter diagram

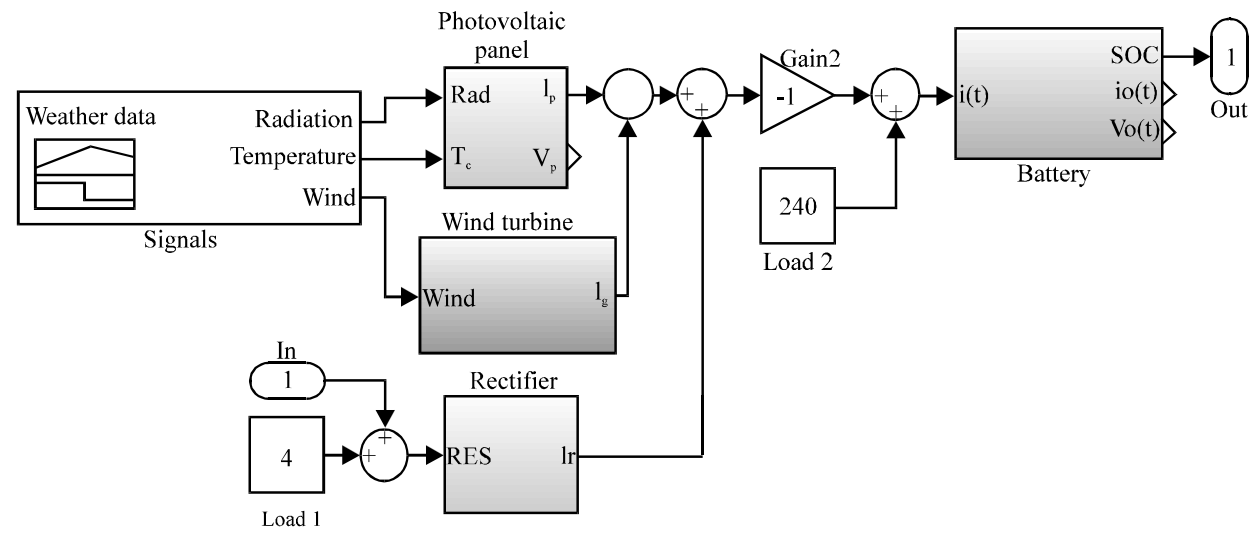

Fig. 3: Micro grid representation

Table 1: Model initial conditions

\begin{tabular}{lr}
\hline Condition & Values \\
Wind turbine & 0.0001 \\
Battery model & 498960 \\
Buck converter & 1 \\
Photovoltaic panel & 0 \\
\hline
\end{tabular}

Buck converter model: The typology of Buck converter is shown in Fig. 2 with a power switch S, Inductor I and Capacitor $\mathrm{C}$. The resistance $\mathrm{R}$ represents the load on the battery circuit. This converter is attempted to emulate a diesel power source which is commonly present in isolated power systems (Katiraei and Abbey, 2007). The dynamic process of the circuit can be described by the ordinary differential Eq. 11 and 12. Buck response was controlled by a discrete time servo system:

$$
\begin{aligned}
& \mathrm{I}, \frac{\mathrm{di}}{\mathrm{dt}}=-v+\mathrm{Eu} \\
& \mathrm{C} \frac{\mathrm{d} v}{\mathrm{dt}}=\mathrm{i}-\mathrm{R} v
\end{aligned}
$$

Micro-grid system: The micro-grid was designed to be modeled as shown in Fig. 3. When the individual renewable source representation is obtained it is integrated into the micro grid to get the final mathematical model in this case is required the application of linearization techniques that provides a lot of insight about its dynamics. From above, MATLAB provide a linear analysis tool, helpful to get the linearization model using the simulink representation as shown in Fig. 3. In this tool is required define the operating point in this case we use the model initial conditions as shown in Table 1.

The toolbox show the space state, the zero-pole gain and the transfer function representation but in this case it is implemented the transfer function in the Eq. 13 to calculate a generalized predictive control:

$$
G(z)=\frac{0.0002535 z^{3}+1.31 e^{-5} z^{2}+5.381 e^{-5} z-9.82 e^{-46}}{z^{4}-z^{3}+9.517 \mathrm{e}^{-10} z^{2}-3.952 \mathrm{e}^{-35} z-8.246 \mathrm{e}^{-67}}
$$

\section{MATERIALS AND METHODS}

CARIMA Model in a GPC with measurement disturbances model: The common SISO transfer function model in GPC is the CARIMA Model because it 
considered the uncertainty that could have a non-zero steady state in its representation, so in Eq. 14 is shown its mathematical expression (Ordys, 2001). Where $\varsigma_{\mathrm{k}}=0$ means a random variable and $T(z)$ is treated as a design parameter. For convenience the CARIMA Model can be expressed as shown Eq. 16 where $[\mathrm{a}(\mathrm{z}) \Delta]$ is a combination between $\mathrm{a}(\mathrm{z})$ and delta $(\Delta)$ and $\Delta \mathrm{u}_{\mathrm{k}}$ use input increments with $\Delta=1-\mathrm{z}^{-1}$ (Rodriguez and Dumur, 2005; Guo et al., 2008):

$$
\mathrm{a}(\mathrm{z}) \mathrm{y}_{\mathrm{k}}=\mathrm{b}(\mathrm{z}) \mathrm{u}_{\mathrm{k}}+\mathrm{d}(\mathrm{z}) \mathrm{v}_{\mathrm{k}}+\mathrm{T}(\mathrm{z}) \frac{\mathrm{c}_{\mathrm{k}}}{\Delta}
$$

where, $d(z) v_{k}$ is the representation of disturbances transfer function. For convenience, the CARIMA Model can be expressed as is shown in Eq. 15 where $[\mathrm{a}(\mathrm{z}) \Delta]$ is a combination between $\mathrm{a}(\mathrm{z})$ and delta $(\Delta), \Delta \mathrm{u}_{\mathrm{k}}$ use input increments and $\Delta \mathrm{u}_{\mathrm{k}}$ use disturbances increments with $\Delta=1-z^{-1}$ :

$$
[\mathrm{a}(\mathrm{z}) \Delta] \mathrm{y}_{\mathrm{k}}=\mathrm{b}(\mathrm{z})\left[\Delta \mathrm{u}_{\mathrm{k}}\right]+\mathrm{d}(\mathrm{z})\left[\Delta v_{\mathrm{k}}\right]+\mathrm{T}(\mathrm{z}) \varsigma_{\mathrm{k}}
$$

Another way to represent the CARIMA Model is through Eq. 16. In SISO Models the $b(z)$ and $A(z)$ are given by the numerator and denominator of transfer function as shown in Eq. 17 and 18. While d(z) are given by the numerator of disturbance model as is shown in Eq. 19:

$$
\begin{gathered}
\mathrm{A}(\mathrm{z}) \mathrm{y}_{\mathrm{k}}=\mathrm{b}(\mathrm{z})\left[\Delta \mathrm{u}_{\mathrm{k}}\right]+\mathrm{d}(\mathrm{z})\left[\Delta v_{\mathrm{k}}\right]+\mathrm{T}(\mathrm{z}) \zeta_{\mathrm{k}} \\
\mathrm{b}(\mathrm{z})=\mathrm{b}_{1} \mathrm{z}^{-1}+, \ldots,+\mathrm{b}_{\mathrm{m}} \mathrm{z}^{-\mathrm{m}} \\
\mathrm{A}(\mathrm{z})=1+\mathrm{A}_{1} \mathrm{z}^{-1}+, \ldots,+\mathrm{A}_{\mathrm{n}} \mathrm{z}^{-\mathrm{n}} \\
\mathrm{d}(\mathrm{z})=\mathrm{d}_{0}+\mathrm{d}_{1} \mathrm{z}^{-1}+, \ldots,+\mathrm{d}_{\mathrm{p}} \mathrm{z}^{-\mathrm{p}}
\end{gathered}
$$

In this step it is use the same recursively concept integrated the $d(z)$. To have an appropriate notation it is considered the system in terms of matrix and vectors as shown in Eq. 20:

$$
\begin{aligned}
& \mathrm{y}_{\mathrm{k}+1}=\mathrm{H} \stackrel{\Delta}{\rightarrow} \mathrm{u}_{\mathrm{k}}+\mathrm{P} \stackrel{\Delta}{\leftarrow} \mathrm{u}_{\mathrm{k}-1}+\mathrm{E} \stackrel{\Delta}{\rightarrow} \mathrm{v}_{\mathrm{k}}+ \\
& \mathrm{G} \stackrel{\Delta}{\leftarrow} \mathrm{v}_{\mathrm{k}-1}-\mathrm{Qy}_{\leftarrow \mathrm{k}}
\end{aligned}
$$

where, $\mathrm{H}=\mathrm{C}_{\mathrm{A}}^{-1} \mathrm{C}_{\mathrm{b}}, \mathrm{P}=\mathrm{C}_{\mathrm{A}}^{-1} \mathrm{H}_{\mathrm{b}},=\mathrm{C}_{\mathrm{A}}^{-1} \mathrm{C}_{\mathrm{d}}, \mathrm{G}=\mathrm{C}_{\mathrm{A}}^{-1} \mathrm{H}_{\mathrm{d}} \mathrm{y}, \mathrm{Q}=\mathrm{C}_{\mathrm{A}}^{-1} \mathrm{H}_{\mathrm{A}}$. The $\mathrm{H}, \mathrm{P}, \mathrm{E}, \mathrm{G}$ and $\mathrm{Q}$, matrix dimension are determinates by the prediction and control horizons.
Control law: To develop a GPC law algorithm the unbiased cost $(\mathrm{J})$ as shown in Eq. 22 is defined. Where $e_{k+1}=r_{k+1}-y_{k+1}$ and $\lambda$ is a constant value between 0 and 1 , that determines the controller robustness:

$$
\mathrm{J}=\mathrm{e}_{\rightarrow \mathrm{k}+1}^{\mathrm{T}} \mathrm{e}_{\mathrm{k}+1}+\lambda \Delta \mathrm{u}_{\rightarrow \mathrm{k}}^{\mathrm{T}} \Delta \mathrm{u}_{\rightarrow \mathrm{k}}
$$

It must consider the same unbiased cost showed in Eq. 14. Consequently, we can perform a minimization to find the optimum J value. So, considering Eq. 21 is necessary replace it to get a representation with the past and future values as shown in Eq. 22 (Zhou and 2006):

$$
\begin{aligned}
& \mathrm{J}=\left[\mathrm{r}_{\rightarrow \mathrm{k}+1}^{\mathrm{T}}-\mathrm{P}^{\mathrm{T}} \stackrel{\Delta}{\leftarrow} \mathrm{u}_{\mathrm{k}-1}-\mathrm{E}^{\mathrm{T}} \stackrel{\Delta}{\rightarrow} \mathrm{v}_{\mathrm{k}}-\mathrm{G}^{\mathrm{T}} \stackrel{\Delta}{\leftarrow} \mathrm{v}_{\mathrm{k}-1}+\mathrm{Q}^{\mathrm{T}} \mathrm{y}_{\leftarrow \mathrm{k}}\right] \times \\
& {\left[\mathrm{r}_{\rightarrow \mathrm{k}+1}-\mathrm{P} \stackrel{\Delta}{\leftarrow} \mathrm{u}_{\mathrm{k}-1}-\mathrm{E} \stackrel{\Delta}{\rightarrow} \mathrm{v}_{\mathrm{k}}-\mathrm{G} \stackrel{\Delta}{\leftarrow} \mathrm{v}_{\mathrm{k}-1}+\mathrm{Qy}_{\leftarrow \mathrm{k}}\right]+} \\
& {\left[\left(\mathrm{H} \stackrel{\Delta}{\rightarrow} \mathrm{u}_{\mathrm{k}}\right)^{\mathrm{T}}\right] \times\left[\mathrm{H} \stackrel{\Delta}{\rightarrow} \mathrm{u}_{\mathrm{k}}\right]-\left[2\left(\mathrm{H} \stackrel{\Delta}{\rightarrow} \mathrm{u}_{\mathrm{k}}\right)^{\mathrm{T}}\right] \times} \\
& {\left[\mathrm{r}_{\rightarrow \mathrm{k}+1}-\mathrm{P} \stackrel{\Delta}{\leftarrow} \mathrm{u}_{\mathrm{k}-1}-\mathrm{E} \stackrel{\Delta}{\rightarrow} \mathrm{v}_{\mathrm{k}}-\mathrm{G} \stackrel{\Delta}{\leftarrow} \mathrm{v}_{\mathrm{k}-1}+\mathrm{Qy}_{\leftarrow \mathrm{k}}\right]+} \\
& \lambda \Delta \mathrm{u}_{\rightarrow \mathrm{k}}^{\mathrm{T}} \Delta \mathrm{u}_{\rightarrow \mathrm{k}}
\end{aligned}
$$

Considering the above equation it can eliminate the past terms because they do not affect the values that should be minimized in the optimization rule. In the optimization of the cost function J exist an only minimum defined by a gradient equal zero, so, the optimum is given by Eq. 23 :

$$
\begin{aligned}
\Delta \mathrm{u}_{\rightarrow \mathrm{k}}= & \left(\mathrm{H}^{\mathrm{T}} \mathrm{H}+\lambda \cdot \mathrm{I}\right)^{-1} \mathrm{H}^{\mathrm{T}} . \\
& {\left[\mathrm{r}_{\rightarrow \mathrm{k}+1}-\mathrm{P} \stackrel{\Delta}{\leftarrow} \mathrm{u}_{\mathrm{k}-1}-\mathrm{E} \stackrel{\Delta}{\rightarrow} v_{\mathrm{k}}-\mathrm{G} \stackrel{\Delta}{\leftarrow} v_{\mathrm{k}-1}+\mathrm{Qy}_{\leftarrow \mathrm{k}}\right] }
\end{aligned}
$$

The control law equation is determinate by a $\mathrm{k}$ constant defines by the first row of matrix $\left(\mathrm{H}^{\mathrm{T}} \mathrm{H}+\lambda \mathrm{I}\right)^{-1} \mathrm{H}^{\mathrm{T}}$, multiply by $\Delta \mathrm{u}_{-\mathrm{k}}$ as shown in Eq. 24 (Hou et al., 2014):

$$
\begin{aligned}
\Delta \mathrm{u}_{\rightarrow \mathrm{k}}=\mathrm{k} \cdot\left(\mathrm{H}^{\mathrm{T}} \mathrm{H}+\lambda \cdot \mathrm{I}\right)^{-1} \mathrm{H}^{\mathrm{T}} . \\
\quad\left[\mathrm{r}_{\rightarrow \mathrm{k}+1}-\mathrm{P} \stackrel{\Delta}{\leftarrow} \mathrm{u}_{\mathrm{k}-1}-\mathrm{E} \stackrel{\Delta}{\rightarrow} v_{\mathrm{k}}-\mathrm{G} \stackrel{\Delta}{\leftarrow} v_{\mathrm{k}-1}+\mathrm{Qy}_{\leftarrow \mathrm{k}}\right]
\end{aligned}
$$

To design a block diagram simulation is required unpack each term of the $\mathrm{u}_{\mathrm{k}}$ equation in vectors as shown in Eq. 25. Then the GPC control law is summarized as is shown in Eq. 26: 


$$
\begin{gathered}
\mathrm{P}_{\mathrm{r}}=\mathrm{k}\left(\mathrm{H}^{\mathrm{T}} \mathrm{H}+\lambda \cdot \mathrm{I}\right)^{-1} \mathrm{H}^{\mathrm{T}} \\
\mathrm{D}_{\mathrm{k}}=\mathrm{P}_{\mathrm{r}} \mathrm{P} \\
\mathrm{N}_{\mathrm{k}}=\mathrm{P}_{\mathrm{r}} \mathrm{Q} \\
\mathrm{R}_{\mathrm{k}}=\mathrm{P}_{\mathrm{r}} \mathrm{E} \\
\mathrm{S}_{\mathrm{k}}=\mathrm{P}_{\mathrm{r}} \mathrm{G} \\
\Delta \mathrm{u}_{\mathrm{k}}=\mathrm{P}_{\mathrm{r}} \mathrm{r}_{\rightarrow \mathrm{k}+1}-\mathrm{D}_{\mathrm{k}} \Delta \mathrm{u}_{\mathrm{k}}-\mathrm{R}_{\mathrm{k}} \stackrel{\Delta}{\rightarrow} v_{\mathrm{k}+1}-\mathrm{s}_{\mathrm{k}} \stackrel{\Delta}{\leftarrow} v_{\mathrm{k}}-\mathrm{N}_{\mathrm{k}} \mathrm{y}_{\leftarrow \mathrm{k}}
\end{gathered}
$$

The final representation $\mathrm{u}_{\mathrm{k}}$ is shown in Eq. 27:

$$
\mathrm{u}_{\mathrm{k}}=\left[\left(1-\mathrm{D}_{\mathrm{k}}\right) \Delta\right]^{-1}\left(\mathrm{P}_{\mathrm{r}} \mathrm{r}_{\rightarrow \mathrm{k}+1}-\mathrm{R}_{\mathrm{k}} \stackrel{\Delta}{\rightarrow} v_{\mathrm{k}+1}-\mathrm{s}_{\mathrm{k}} \stackrel{\Delta}{\leftarrow} v_{\mathrm{k}}-\mathrm{N}_{\mathrm{k}} \mathrm{y}_{\leftarrow \mathrm{k}}\right)
$$

\section{RESULTS AND DISCUSSION}

Then, the GPC behavior is simulated using the structure in Fig. 4. Considering the above, the block simulation in Simulink/MATLAB is shown in Fig. 5. Then, it is proposed a control block followed by a switch block that allows charge the battery in specific cases. Then it is found the rectifier block that give the current to charge the batteries. Finally, it is considered the battery system with measurement disturbances.

To develop the control system, a control horizon of 320 and prediction horizon of 720 with a lambda of 1 . Then, it is obtained as result a charge battery behavior in Fig. 6 with disturbances with a signal control in Fig. 7 and rectifier response in Fig. 8.

Figure 9 It is attempted a cycle of charge and discharge intended to emulate an entire micro grid system duty cycle. Figure 10 shows the rectifier behavior with disturbances and working under a micro grid system duty cycle.

The micro grid system duty cycle was designed in order to maximize the batteries cycle life that in accordance with their datasheet it must not exceed $30 \%$ of depth of discharge. This duty cycle variates from $70-95 \%$ the SOC and emulates 2 days of continue work at the microgrid facilities located inside the Nueva Granada Military University Campus.

In order to test the performance and behavior from this GPC, two controllers were proposed to be compare and tested in the micro grid system. The first controller designed was a classical Proportional-Integral-Derivative (PID) control. Taking advantage from the Ident Toolbox of MATLAB; the micro grid DC system was identified and represented as the model given in Eq. 28:

$$
\mathrm{G}(\mathrm{s})=\frac{2.666 \mathrm{e}^{-5}}{0.4814 \mathrm{~S}^{2}+\mathrm{S}}
$$

Once the model was obtained and using MATLAB Simulink Toolbox, a PID controller was simulated based on system model and transfer function. After simulate the micro grid response with the PID controller Fig. 11. The battery State of Charge (SOC) was referenced to $70 \%$ and the disturbance model simulated 2 days of work in the micro grid DC system shown in Fig. 12.

Figure 13 shows how the controller behaves against disturbances and how its response is to reach the desired reference. Figure 14 it is presented a close up of the controller response when the system has reached the steady state.

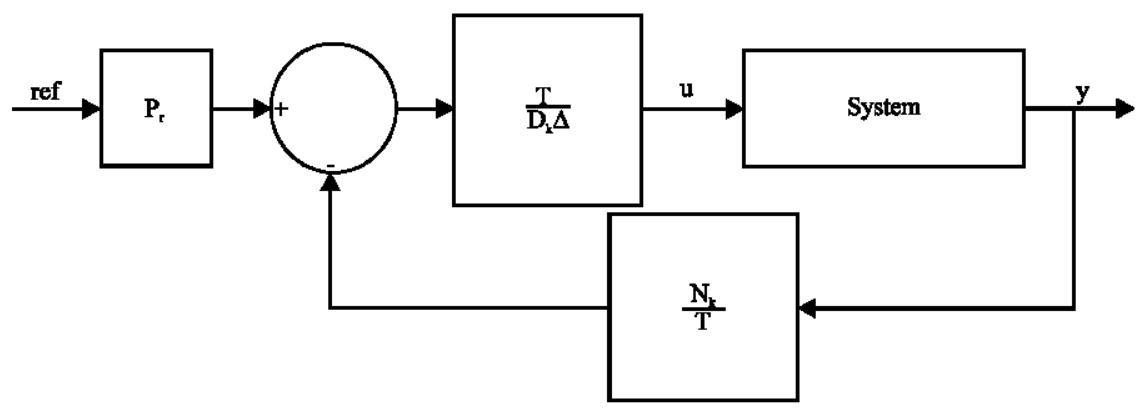

Fig. 4: GPC controller simulation diagram

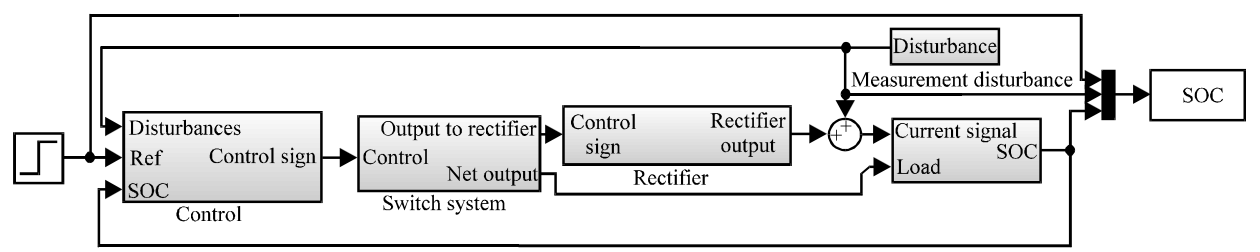

Fig. 5: Micro-grid control diagram 


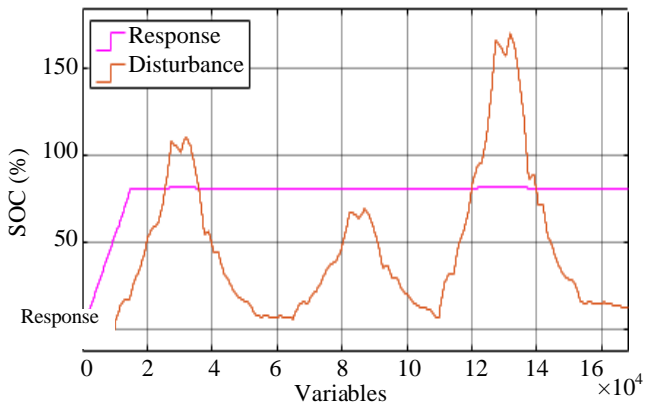

Fig. 6: Behavior of battery charge with GPC $80 \%$ SOC

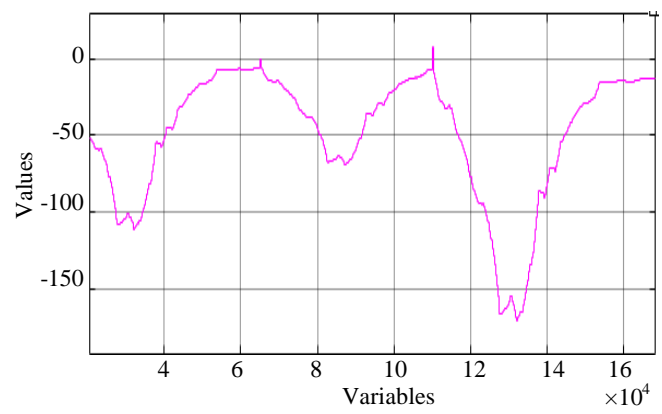

Fig. 7: Control signal with disturbances

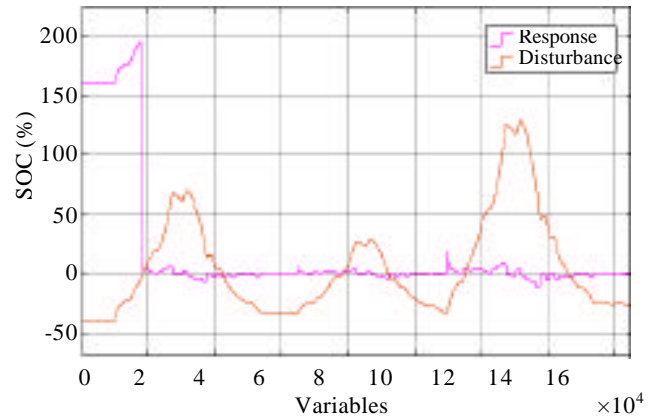

Fig. 8: Rectifier signal response with disturbances

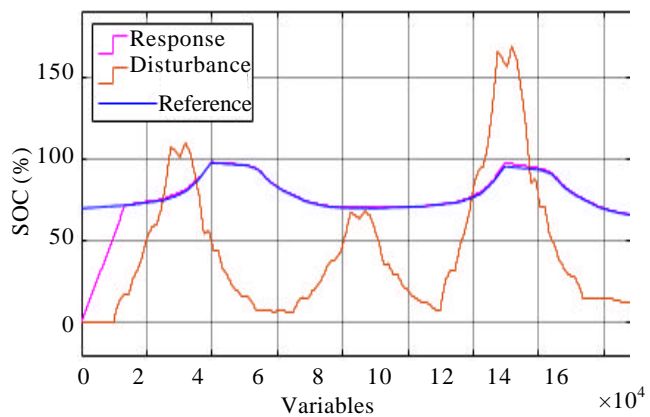

Fig. 9: Response simulating ideal \%SOC according to the desire behavior of battery charge

The second controller tried was a MPC controller. This was implemented by using MPC designer toolbox from MATLAB this toolbox allows to define the desired

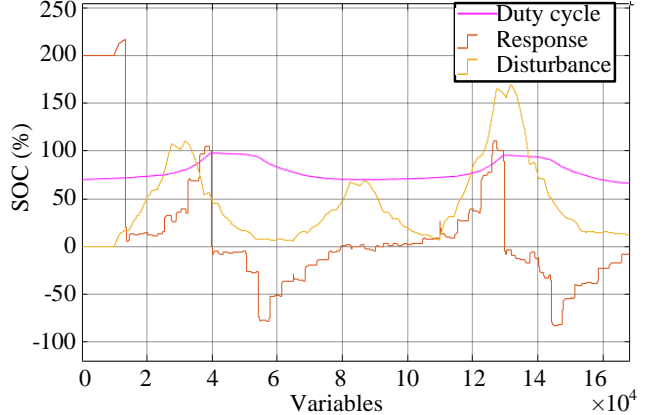

Fig. 10: Rectifier response according micro-grid system duty cycle with disturbances

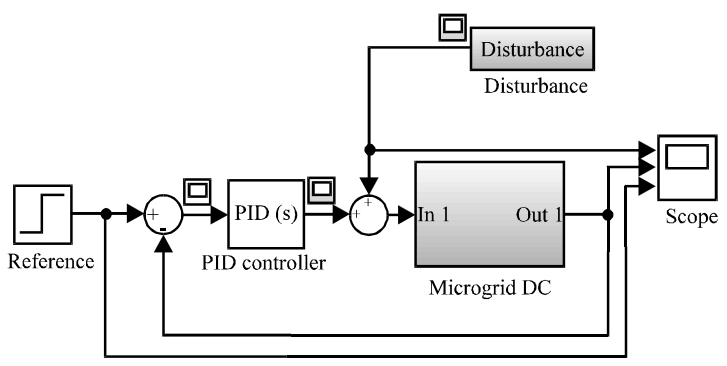

Fig. 11: Micro grid PID control diagram and disturbances

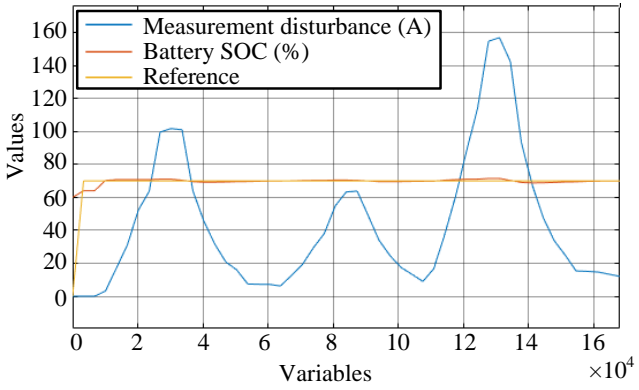

Fig. 12: Battery SOC response with classical PID controller and disturbances

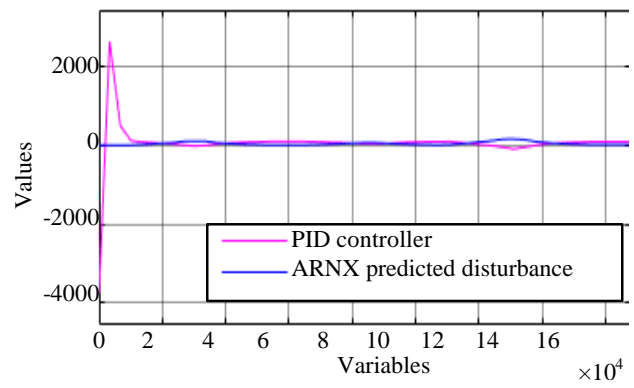

Fig. 13: PID control response with disturbances

controller structure. Figure 15 shows the way how the controller structure was declared it has three inputs: Measured Disturbances (MD), Measured Output (MO) and reference (ref) and one output noted as Manipulated Variable (MV). 


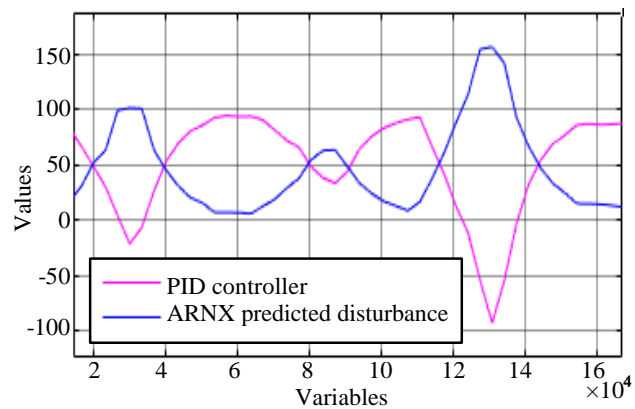

Fig. 14: PID control response with disturbances in steady state

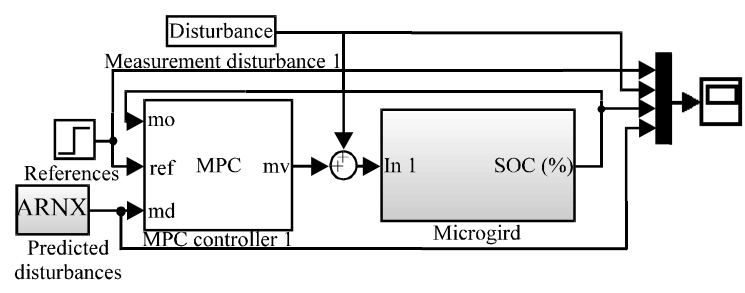

Fig. 15: Microgrid with MPC toolbox control from MATLAB diagram and disturbances predicted by ARNX Model

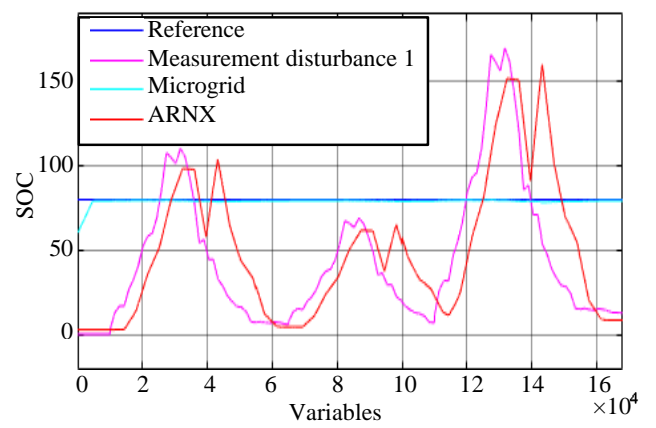

Fig. 16: Battery SOC response with MPC toolbox control from MATLAB diagram and disturbances predicted by ARNX mode

In order to maintain the MPC design as similar as the GPC already presented, the sample time, prediction horizon and control horizon were settled at $10 \mathrm{sec}, 720$ and 360 , respectively. Close-loop performance was stablished as aggressive and state estimation as faster. This kind of controllers offers as big advantage the possibility of set constraints according to the system desired behavior. In this case due to system features the output for the controller was constrained from $0-200 \mathrm{~A}$.

Figure 16 and 17 shows the Battery SOC response with the MPC. Due the robustness of this design, the output signal stabilizes near to the reference but it never exceeds the desired percentage of charge.

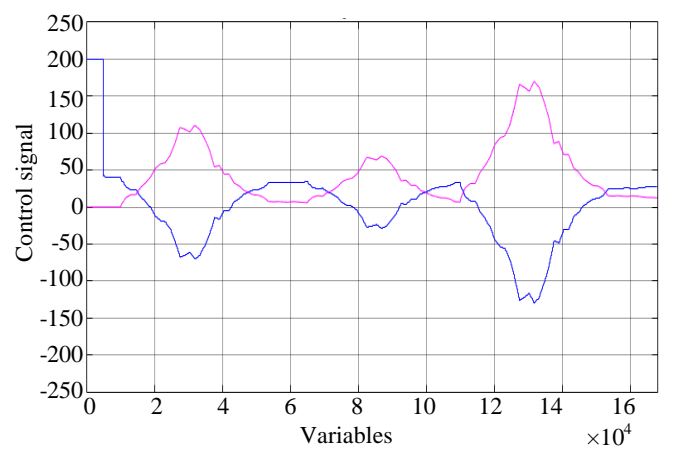

Fig. 17: MPC control response with disturbances predicted by ARNX Model

Table 2: PID tuning parameters

\begin{tabular}{ll}
\hline PID tuning parameters & Values \\
\hline $\mathrm{K}_{\mathrm{p}}$ & 36.98 \\
$\mathrm{~K}_{\mathrm{i}}$ & 0.00653 \\
$\mathrm{~K}_{\mathrm{d}}$ & 7022.5 \\
\hline
\end{tabular}

Table 3: Controllers comparison

\begin{tabular}{lrrr}
\hline Parameter & GPC & PID & MPC \\
\hline Max. error SS (\%) & 1.563 & 2.161 & 0.3833 \\
Max. Current peak.SS (A) & 47.53 & 94.08 & 33.82 \\
Power consumption kWh & 2.28 & 4.5 & 1.6 \\
Approx. settling time (sec) & 140000 & 10000 & 7000 \\
\hline
\end{tabular}

Once all three controllers were tested and after simulate the controllers performance, parameters of comparison were taken and noted in Table 2. For this study were evaluated four parameters.

The first parameter was the maximal percentage of error in the output signal understood as the SOC in the micro grid. In all three cases, the percentage of error did not exceed levels that can generate significant damage to the batteries or shorten their cycle life. The second parameter tested was the maximal peak of current in steady state. This parameter is important because micro grids DC look for minimize and optimize power consumption. As shows Table 3, PID controller is the worst option to be implemented in this kind of DC systems, this controller shows a reactive response against disturbance and this behavior generates peak of current that can damage the batteries and shorten their cycle life. The power consumption parameter is calculated under the postulate that the maximum current is the nominal current in the micro grid this shows the PID as the worst control solution to enhance the efficiency in these systems.

Finally, an approximate settling time is evaluated; this settling time should be as similar to the batteries charging time as possible. According to the battery model simulated in the micro grid this time is $4 \mathrm{~h}$. Therefore, the GPC would be the best choice to be taken in this parameter, faster charging time would damage the batteries and shorten their cycle life. 


\section{CONCLUSION}

This study has shown that different techniques of control can be implemented in this micro grid system, the difference lays on the level of performance and efficiency desired for the system. The GPC designed has demonstrated good performance under disturbances and it has shown a behavior similar to the MPC designed by toolbox in MATLAB. In the other hand, the PD controller has shown low performance compare to the other controllers, nonetheless it could be a good option whether the issue is charge the storage system and maintain this under desired reference. Finally, it is possible to conclude that methods of control as the GPC or MPC, lead to best performance and behavior inside this micro grid system over classical controllers like $\mathrm{PD}$ which are more likely to generate over consumption, low performance and low efficiency. Further works are leading to implement this controller on real micro grid DC system, looking to create a small smart grid.

\section{ACKNOWLEDGEMENT}

The research for this study was supported by Universidad Militar Nueva Granada, through the project INV-ING 2390.

\section{REFERENCES}

Anonymous, 2008. Federal energy regulatory commission assessment of demand response and advanced metering, staff report and excel data. Federal Energy Regulatory Commission, Washington D.C., USA.

Anonymous, 2014. [Energy solutions for the noninterconnected areas of Colombi]. Instituto de Planificación y Promoción de Soluciones Energéticas para las Zonas No Interconectadas-IPSE, Spain, Europe. (In Spanish) https: //www. minm inas.g ov.co /docume nts/10180/742159/09C-Solucion esEn erget icasZNI-IPSE.pdf/2871b35d-eaf7-4787-b778-ee73b1

Anonymous, 2017a. Electricity generation-what are the options? World Nuclear Association, London, England, UK. http://www.world-nuclear.org/nuclearbasics/electricity-generation-what-are-theoptions.aspx

Anonymous, 2017b. Renewables 2017 global status report. REN21, Paris, France. http://www.ren21. net/gsr-2017/

Chidrawar, S. and B. Patre, 2008. Generalized predictive control and neural generalized predictive control. Leonardo J. Sci., 7: 133-152.

Clarke, D.W., C. Mohtadi and P.S. Tuffs, 1987. Generalized predictive control-Part I. The basic algorithm. Autom., 23: 137-137.
Guo, W., W. Wang and X. Qiu, 2008. An improved generalized predictive control algorithm based on PID. Proceedings of the 2008 International Conference on Intelligent Computation Technology and Automation (ICICTA'08) Vol. 1, October 20-22, 2008, IEEE, Hunan, China, ISBN:978-0-7695-3357-5, pp: 299-303.

Holkar, K.S. and L.M. Waghmare, 2010. An overview of model predictive control. Intl. J. Control Autom., 3: 47-63.

Hou, G., X. Bai and R. Huang, 2014. Application of improved generalized predictive control to coordinated control system in supercritical unit. Proceedings of the 2014 IEEE 9th Conference on Industrial Electronics and Applications (ICIEA'14), June 9-11, 2014, IEEE, Hangzhou, China, ISBN:978-1 4799-4314-2, pp: 1591-1595.

Katiraei, F. and C. Abbey, 2007. Diesel plant sizing and performance analysis of a remote wind-diesel microgrid. Proceedings of the 2007 IEEE International Conference on Power Engineering Society General Meeting, June 24-28, 2007, IEEE, Tampa, Florida, pp: $1-8$.

Mauledoux, M., O.I. Caldas and E. Mejia-Ruda, 2015. Comparative study of various models to estimate hourly solar irradiance: Application for performance analysis of a renewable energy DC-Micro grid. Appl. Mech. Mater., 700: 7-11.

Mork, B.A. and W.W. Weaver, 2009. Smart grids and micro-grids: What are they really. Proceedings of the 2009 International Conference on Minnesota Power Systems, November 3-5, 2009, Brooklyn Center, Minnesota, USA., pp: 1-21.

Olivares, D.E., A. Mehrizi-Sani, A.H. Etemadi, C.A. Canizares and R. Iravani et al., 2014. Trends in microgrid control. IEEE. Trans. Smart Grid, 5: 19051919.

Ordys, A.W., 2001. Predictive control for industrial applications. Ann. Rev. Control, 25: 13-24.

Rodriguez, P. and D. Dumur, 2005. Generalized predictive control robustification under frequency and timedomain constraints. IEEE. Trans. Control Syst. Technol., 13: 577-587.

Tang, C.Y., Y. Guo and J.N. Jiang, 2011. Nonlinear dualmode control of variable-speed wind turbines with doubly fed induction generators. IEEE. Trans. Control Syst. Technol., 19: 744-756.

Zhou, L. and D. Qu, 2006. Study of generalized predictive control scheme and algorithm based on artificial neural network. Proceedings of the 2006 IEEE International Conference on Information Acquisition, August 20-23, 2006, IEEE, Weihai, China, ISBN:14244-0528-9, pp: 1208-1212. 